Review Article

\title{
Documentation of Major Poisonous Plant on Livestock in Ethiopia
}

\author{
Temesgen Kassa Getahun, Wondimu Debash Beze \\ Ethiopian Institute of Agricultural Research Holeta Agricultural Research Center Animal Health Research, Holeta, Ethiopia \\ Email address: \\ Temesgen.kassa@yahoo.com (T. K. Getahun)
}

To cite this article:

Temesgen Kassa Getahun, Wondimu Debash Beze. Documentation of Major Poisonous Plant on Livestock in Ethiopia. Journal of Diseases and Medicinal Plants. Vol. 5, No. 2, 2019, pp. 39-44. doi: 10.11648/j.jdmp.20190502.13

Received: February 26, 2019; Accepted: April 3, 2019; Published: June 20, 2019

\begin{abstract}
The review was conducted with the objective of documenting potentially poisonous plants in Ethiopia. One of the major causes of economic loss in the livestock industry is Poisonous plants especially in the developing country including Ethiopia. In each year poisonous plant affect 3 to 5 percent of the cattle, sheep, goat, and horses that graze ranges. Major loss caused by these plants result from death of livestock, abortions, photosensitization, decreased production, emaciation, and birth defects and also they have other losses due to increased management costs associated with such things as fencing to prevent access of animals to these plants, altered grazing programs, and loss of forage due to removal of these plants. Livestock mostly exposed to toxic plants in dry and early rainy season when feed is in short supply. In this documentation 71 different plants identified from four different area of the country were collected from different governmental and non-governmental organizations and published papers. A more extensive survey is required to document all poisonous plants in the rangelands and to identify the major toxic principles in the different species possibly pharmacological activity. This documentation review the current knowledge on the identity of plants known to have poisoned livestock and research conducted into these toxic plants.
\end{abstract}

Keywords: Animal Health, Documentation, Poisonous Plant

\section{Introduction}

Livestock are facing various life threatening hazards notably infectious (parasitic, bacterial, viral, protozoal, fungal) and noninfectious like metabolic diseases, poisoning and other miscellaneous origin. Toxic plants affecting both large and small animals are a major concern for the practicing veterinarian and livestock producer in every country. Many studies showed that toxic plants affecting both large and small animals are a major concern for the practicing veterinarian and livestock producer in every country of the world. In countries with higher plant biodiversity, the number of problematic toxic plants may be greater [1], despite there are plants that played a central part in combating many aliments in human and livestock in many indigenous communities, in the world including Africa. Ethiopia also possesses three traditionally recognized agro climatic zones. These are Kola (a hot zone of 500-1500 m above sea level), Weina Dega (intermediate zone of $1500 \mathrm{~m}$ and $2500 \mathrm{~m}$ ), and Dega (a cold zone usually cited as being $250 \mathrm{~m}$ above sea level). These ecological zones have favorable to various species of plants and animals. Apart from the globally listed ones, therefore, some factors are inherent in Ethiopia to contribute to phytotoxicity [2].

Plants have played a central part in combating many ailments in human and livestock in many indigenous communities, including Africa. Ethiopia, which is located in the Horn of Africa between 3 to $15^{\circ} \mathrm{N}$ and 33 to $48^{\circ} \mathrm{E}$ longitude is a country with varied climatic conditions. The temperature varies from $10^{\circ} \mathrm{C}$ to $45^{\circ} \mathrm{C}$ [3]. This varied climatic condition enables the country to have diverse flora and fauna that are unique of which $12 \%$ are endemic. Despite the fact the forest is declining in size and quantity, the contributions to the national and local economy from forest resources are of immense value [4].

Plants take the third largest category of poisons known around the world. The effect of this toxic plants on animals amplified as they form a major part of livestock feed, thus toxicosis in animals consuming these plants can be expected. Forage crops may sometimes contain compounds that may 
inadvertently affect animals. Several factors contribute to an animal being poisoned by plants. Fundamentally, there is the requirement that a sensitive species of animal ingest, or otherwise be exposed to, a toxic plant at an appropriate time. There are many examples of species differences with regard to sensitivity to the toxic effects of plants. In addition, it is possible for animal species to adapt to a potentially toxic plant if exposure is allowed to occur over a period of time. Disease problems are most commonly caused by forage contaminated with poisonous weeds [5].

A variety of poisonous plants have caused extensive losses to the livestock industry in many parts of the world mainly east Africa including Ethiopia since the days of early settlement. They are still significant problems in numerous areas. Poisonous plants produce their toxic effects after being ingested and/or absorbed by animals which include physical upset, loss of productivity and death. Therefore, even though plants have vital nutritious and providing the normal atmospheric oxygen, it will cause life threatening if it is toxic [6].

Plant poisoning is due to either accidental ingestion of material eaten along with grass or willful consumption of poisonous plants when pasture is dry while most poisonous plants remain green all the year round. It is also more likely to occur in animals which have been moved from one part of the country to another. New importations are unfamiliar with the strange ingestion of their fresh surrounding. Acclimatization in herbivores animals induces a sense of discrimination between edible and non-edible parts [7]. Even though animals are selective about what they eat, there are instances (for example, herbicide applications) that may change palatability or increase toxicity of some plants. If weeds are embedded in hay cubes, animals may not be able to avoid ingestion of the weeds [5].

Livestock poisoning occurs when animals consume these plants in large amount in a short period or graze over a prolonged period of time. Most of the poisonous plants remain green and attractive for hungry and thirsty animals. Animals under nutritional stress may be less able to detoxify plant toxins and may suffer relatively greater harm from the metabolic effects of the toxins. Thus, proper observation of grazing animals, good grazing management with prior knowledge of poisonous plants in the rangelands, and strategic supplemental feeding may help to mitigate the problem [8]. The poisonous plants reported in this review include both herbaceous and woody species.

The loss may be in the form of, mortalities, production, veterinary service fees or a combination of two or more of these losses [9]. The symptoms and lesions differ observed on the affected animals depending on the amount of the plant consumed, age, and species of the animals. Despite the variation in their effect the common clinical signs and symptoms, however include chronic illness and debilitation, decreased weight gain, abortion, abdominal discomfort, salivation, congenital defects, photosensitization and finally death [5]. These symptoms have been attributed to the toxic principle in such plants, which range from nitrates, oxalate, fluroacetate, selenium etc. Both large and small animals are frequently affected by toxic plants and they are a major concern for the practicing veterinarian and livestock producer in every country. In countries with higher plant biodiversity li Ethiopia, the number of problematic toxic plants was greater.

However; this knowledge on poisonous plant has not yet been well documented and so far very little knowledge in Ethiopia is properly documented and analyzed. Moreover, the knowledge of poisonous plant is still mainly orally transmitted from generation to generation, consequently, it remains fragile and threatened, and presents an urgent need for being recorded and documented for prospect management of poisonous plant by livestock owners. Therefore; this study was document poisonous plants in different part of Ethiopia collected by different stack holders to prevent repetition of invitro and field survey work.

\section{Material and Methods}

\subsection{Study Design}

Retrospective study design was used to collect secondry data from different universities and government organizations. Literatures were sighted from different scientific journals reported form different part of Ethiopia.

\subsection{Methods of Data Collection}

The documentation of poisonous plant was proposed to collect information by implementing a retrospective type of study. Hence, a review of available literatures on Ethiopian poisonous plant was carried out. Other main sources were journals, online materials, reports and other relevant, published and unpublished documents by different universities of Ethiopia, regions, zones, districts and kebeles. Google, Pub Med and Medline online searches were also carried out to access other relevant publications.

\section{Result}

This documentation was conducted to document some of poisonous plants collected and identified by different university and other organizations in Ethiopia. From the literatures reviewed in the present study different poisonous plant species were studied by different universities in Ethiopia as it was showed on table one.

Table 1. Documentation of major poisonous plant.

\begin{tabular}{|c|c|c|c|c|c|c|}
\hline Local name & Scientific Name & Toxic part & Effect & Specie affected & Author & Study area \\
\hline $\operatorname{Alma}(\mathrm{A})$ & Rhizophoraceae & NA & Bloating, Colic & Bovine & Dereje & \\
\hline Farmasiisa $(\mathrm{O})$ & Parthenium hysterophorus & NA & Salivation, Sour Milk & Bovine \& Shoats & Abera, & In and around \\
\hline Hamakitaa $(\mathrm{O})$ & Medicago polymorpha & NA & Bloating Colic & Bovine & Tariku Jibat, & Adama town \\
\hline Hasangira $(\mathrm{O})$ & Trifolium burchellianum & NA & Depression, Erection of Hair, Bloating & Bovine & Teshale Sori, & \\
\hline
\end{tabular}




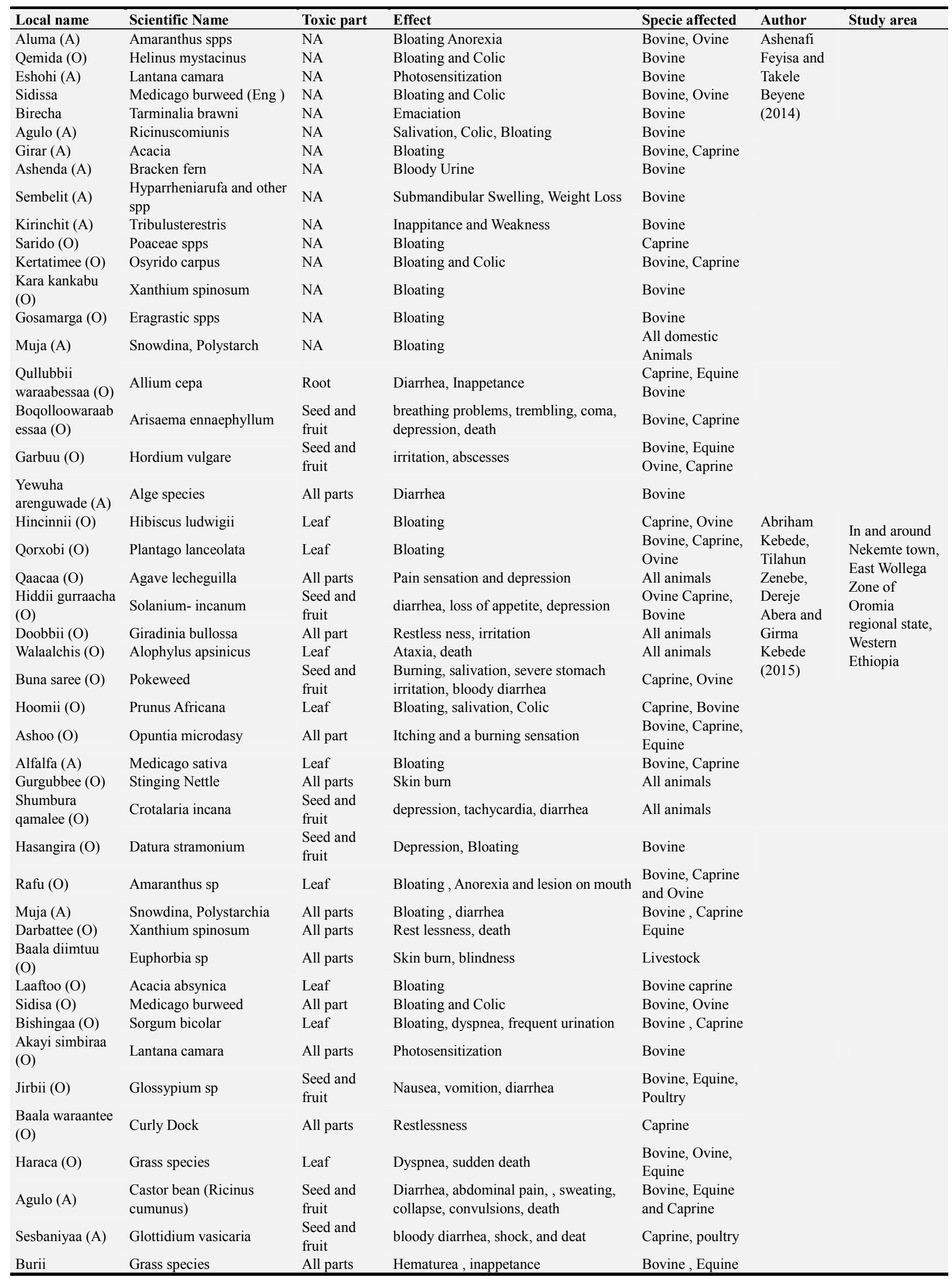




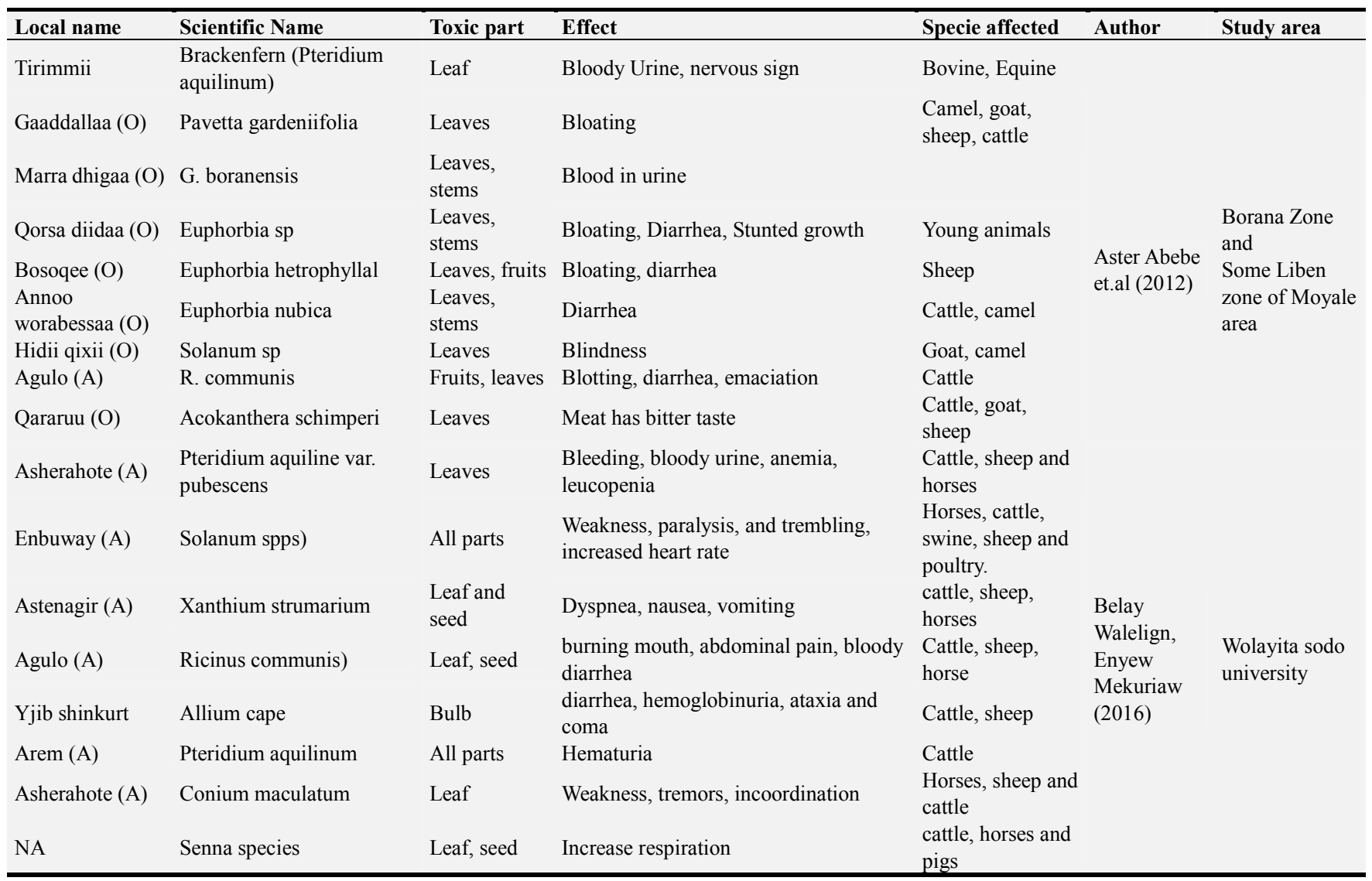

\section{Major Effects on Animal Health and Production}

Plants were grouped based on the major organ system affected by consumption of the plant. The times of the year with higher precipitation rates are April through May and October through November. The start of the rainy period is accompanied by intense growth of some plant species used for animal feed (especially grasses), a situation that is usually associated with increased accumulation of potentially toxic compounds such as nitrates. However, some plants accumulate more toxins during the dry periods accumulates more cyanogenic glycosides during these periods [10].

\subsection{Gastrointestinal System}

Ricinus communis (castor, higuerilla, palmacristi, ricino) is a naturalized plant one of the most potent lectins known. In general lectins cause necrosis of the cells lining the gastrointestinal tract. All animal species are sensitive to the effects of ricin. The toxicosis however is uncommon and it is usually associated with feeding garden clippings or with contamination of forage grasses with $R$. communis trimmings. Clinical signs include weakness, salivation, profuse aqueous diarrhea, dehydration, teeth grinding, and recumbence; the major postmortem finding is severe gastroenteritis [11]. Another plant compound highly irritating to the gastrointestinal mucosa is ricinoleic acid, a fatty acid present in Ricinus communis seeds, considered to be responsible for the cathartic properties of ricin oil. Ricinoleic acid is an irritant that alters the intestinal epithelium causing loss of water and electrolytes, increased loss of luminal DNA, and decreased enzymatic activity of enterocytes [12].

\subsection{Circulatory System}

Allium cape which includes all types of onions is capable of causing toxicosis in both large and small animals due to its content of organic sulfoxide especially alkyl or alkenyl cysteinyl sulfoxide. After ingestion the organosulfoxides are transformed into a complex mixture of organic sulfur compounds some of which are capable of causing intravascular hemolysis in cattle, sheep and horses. The excessive intake of onions leads to hemolytic anemia and methemoglobinemia which develops within a week of onion ingestion. Clinical signs in cattle include diarrhea, hemoglobinuria, ataxia and coma. Cattle are more sensitive than horses and goats are the most resistant. The hemolytic anemia caused by onion ingestion can also occur in dogs and cats.

\subsection{Urinary System}

Urinary bladder tumors in cattle have been associated with the intake of Pteridium aquilinum. This weedy plant found worldwide grows in well-drained, acid soils and open lands. Cattle readily eat the plant when it is still young; old plants are normally not eaten unless there are no other plants in the pasture. This plant contains at least two important toxic 
components: a thiaminase capable of destroying Vitamin B1 and a mutagenic carcinogenic glycoside known as ptaquiloside. The toxicosis results from the chronic intake of ptaquiloside and its major sign is hematuria caused by the development of multiple bleeding tumors in the bladder mucosa $[13,14]$.

\subsection{Nervous System}

Conium maculatum is commonly found along roadsides and close to irrigation waters. Conium maculatum contains at least five main piperidine alkaloids of which of the most important are coniine (mainly in the seeds) and $\gamma$-coniceine (in vegetative tissue). The other three alkaloids are $\mathrm{N}$-methylconine, conhydrine and pseudoconhydrine. In world literature the toxicosis has been reported in horses, pigs, sheep and cattle with cattle the most sensitive species. The initial signs of the acute toxicosis include muscle weakness, tremors, incoordination and mydriasis followed by brady-cardia, depression coma and death from respiratory failure.

\subsection{Musculoskeletal and Connective Tissue}

The genus Senna (formerly known as Cassia) includes several species of plants known to induce myopathy in cattle, horses and pigs that graze on them or that eat feed contaminated with their seeds. Senna toxicosis causes myocardial degeneration, congestive heart failure and generalized degeneration of skeletal muscles. The muscle damage is accompanied by high serum activity of the enzyme aspartate amino transferase (AST) and creatine kinase (CK) and myoglobinuria. At postmortem examination the affected muscles look pale and show whitish striations [15].

\subsection{Skin}

Toxic plant-induced primary and secondary photosensitization is a common cause of skin lesions in livestock throughout the world. Secondary photosensitization results from impaired excretion of phylloerythrin.

\section{Economic impacts of Poisonous Plants on Livestock}

Direct losses of livestock involve the economic impact of poisonous plants on the animal. These losses include such things as: deaths of livestock, abortions, birth defects, weight loss (due to illness or decreased feed intake), lengthened calving interval, decreased fertility, decreased immune response, decreased function due to damage to organs such as the nervous system, lungs, liver, etc., loss of breeding stock due to deaths, functional inefficiency, etc [16]. Indirect losses include those activities or costs that are incurred by a livestock operation to prevent losses or costs incident to livestock poisonings by plants. Indirect losses (cost) include fences built and maintained to manage livestock at risk due to poisonous plants, herding livestock to prevent poisoning, supplemental feeding to prevent poisoning, altered grazing programs which may result in increased costs or grazing inefficiency, medical costs incident to poisoning and forage lost because it could not harvested at the proper time or intensity. These costs are difficult to quantify, yet are present [16].

\section{Conclusion and Recommendations}

Toxic plants can adversely affect every organ system and pose a risk to animal health and production. There are potentially dozens of plant species in and along pastures and meadows and sometimes in hay that can cause toxicity problems to livestock. It is important to be aware of these plants and their toxicity symptoms. There are times such as early spring, during summer or droughts when forage supplies are low and this is when one needs to be most aware of what livestock is grazing. There are also situations where regardless of adequate forage, certain animal just love to browse and end up consuming toxic plants or plant parts. Toxic plants are the major problem of livestock production. Eventhough such problems highly affect then livestock sector, on well-organized information are documented on poisonous plant. For effective prevention and control of plant poisoning it is worthwhile to apply the following fundamental measures as recommendation:

1 Identification of previously unidentified plants that are poisons to the livestock.

2 Improvement of management and hygienic practice of the pasture land.

3 Notifying the problem to the veterinarian personal or toxicologist.

4 Creating awareness of the season of most poisonous plants are growing and cause problem on animal health.

5 Giving adequate feed during drought season

6 Testing plant toxicity and inspection of pasture

7 Documentation of previously identified poisonous plants and awareness creation

\section{References}

[1] Diaz G. J. (2011). Toxic Plants of Veterinary and Agricultural Interest in Colombia, In: Panter EK, and Pfister JA, (Ed.) International Journal of Poisonous Plant Research, A Journal for Research and Investigation of Poisonous Plants.

[2] Mekonnen, Y. (1994): A survey of plants (potentially) toxic to livestock in Ethiopian flora. SINET: Ethiop J Sci 17: 9-32.

[3] Tamire H (1997). Desertification in Ethiopian Highlands. RALA Report No. 200. Norwegian Church AID, Addis Ababa, Ethiopia. pp. 162.

[4] WBISP (Woody Biomass Inventory and Strategic Plan project) (2004). Forest Resources of Ethiopia, Addis Ababa.

[5] Clarke, E. C. G., Clarke, M. L.(1977). Veterinary toxicology. Poisonous plants. Cassel and collier, Macmillian publishers. London pp. 268-277.

[6] Radeleff RD (1964) Veterinary toxicology. London: Bailliere, Tindall \& Cox, USA. 
[7] Mugera GM (1970) Phytolaccadodecandral'Herit toxicity in livestock in Kenya. Bull Epizoot Dis Afr 18: 41-43.

[8] Holechek, J. I. (2002): Do most livestock losses to poisonous plants result from "poor" range management? Journal of Range Management 55: 270-276.

[9] Ogwang BH (1997). A survey of poisonous plants of livestock in Swaziland. Bull. Anim. Health. Prod. Afr. 45: 99-106.

[10] Tokarnia, C. H., J. Döbereiner and P. V. Peixoto. 2002 Poisonous plants affecting Livestock in Brazil. Toxicon 40: 1635-1660.

[11] Aslani, M., Maleki M, and Mohri. M, (2007): Castor bean (Ricinus communis) toxicosis in a sheep flock. Toxicon 49: 400-406.

[12] Bretagne, J. F., Vidon N., Hirondel, C. L. and Bernier, J. J.
(1981): Increased cell loss in the human jejunum induced by laxatives (ricinoleic acid, dioctyl sodium sulphosuccinate, magnesium sulphate, bile salts) 22: 264-269.

[13] Pedraza, C., Villafañe. F and Torrenegra R. D. (1983): Hematuria vesical bovina y su relación con algunas especies vegetales. Revista acove 7: 11-19.

[14] Smith, B. L. (1997) the toxicity of bracken fern (genus Pteridium) to animals and its relevance to man. In J. P. F. D’Mello, ed., Plant and Fungal Toxicants. 63-76.

[15] Barth, A. T., Kommers, G. D., Salles, M. S. (1994): Coffee senna (Senna occidentalis) poisoning in cattle in Brazil. Veterinary and Human Toxicology 36: 541-545.

[16] Nielsen, Darwin, B., and Lynn F., and James. (1991) Poisonous plants-Proc. 3rd Int. Symp, Iowa State Univ. Press, Ames. 